\title{
O VALOR ECONÔMICO DA EXTRAÇÃO MANEJADA DE MADEIRA NO BAIXO AMAZONAS, ESTADO DO PARÁ ${ }^{1}$
}

\author{
Antônio Cordeiro de Santana ${ }^{2}$, Marcos Antônio Souza dos Santos ${ }^{3}$, Ádamo Lima de Santana ${ }^{4}$ e Jorge \\ Alberto Gazel Yared ${ }^{2}$
}

\begin{abstract}
RESUMO - O objetivo deste trabalho foi estimar o valor econômico e a margem de comercialização da madeira em tora oriunda de áreas manejadas. Essa cadeia, além de produzir margem positiva, os valores são relativamente superiores aos gerados nas atividades que concorrem para o desmatamento na Amazônia para se estabelecerem. Adicionalmente, determinou-se o coeficiente médio de desdobramento de 37,3\% (2,68 $\mathrm{m}^{3}$ de madeira em tora para cada 1,0 $\mathrm{m}^{3}$ de madeira serrada), o qual revelou baixo grau tecnológico das empresas. O valor econômico médio da extração e comercialização da madeira em pé no mercado local foi de $\mathrm{R} \$ 23,48 / \mathrm{m}^{3}$, tendo um valor mínimo de $\mathrm{R} \$ 9,06 / \mathrm{m}^{3}$ para as espécies da categoria $\mathrm{C} 4$ (madeira branca) e um máximo de $\mathrm{R} \$ 55,63 / \mathrm{m}^{3}$ para as espécies da categoria $\mathrm{C} 1$ (madeira especial). Assim, para um fluxo de 30 anos e extração de $25 \mathrm{~m}^{3} / \mathrm{ha}$ nos planos de manejo das áreas de concessão florestal do Estado do Pará, gera-se um valor médio de R \$ 587,00/ha, ou R \$ 19,56/ha/ano. No fluxo de 30 anos, esse resultado é relativamente superior ao gerado pelas atividades de pecuária extensiva (em torno de $\mathrm{R} \$ 180,00 / \mathrm{ha}$ ) e das lavouras de grãos (em torno dos $\mathrm{R} \$ 420,00 / \mathrm{ha}$ ), principais responsáveis pelo desmatamento da Amazônia. Também, apresenta maior rentabilidade do que o reflorestamento com paricá, que gera R \$192,26/ha. A margem de comercialização indicou que a sociedade tende a se apropriar de $14,3 \%$ do valor econômico gerado na cadeia da madeira oriunda dos contratos de concessão florestal.
\end{abstract}

Palavras-chave: Preço da madeira em tora, Concessão florestal e Cadeia de valor.

\section{THE ECONOMIC VALUE OF EXTRACTION TIMBER MANAGEMENT IN THE LOWER AMAZON, STATE OF PARÁ}

\begin{abstract}
The objective of this study was to estimate the economic value and the trade margin of roundwood from managed areas. Besides generating t positive margin values, they are relatively higher In this chain than those generated in activities contributing to deforestation in the Amazon. Additionally, the unfolding mean rate of $37.3 \%$ was achieved $\left(2.68 \mathrm{~m}^{3}\right.$ of logs for each $1.0 \mathrm{~m}^{3}$ of sawn timber $)$, which revealed a low technological level of companies. At the lower Amazon, the average economic value from the extraction and sale of standing timber in the local market was $R \$ 23.48 / \mathrm{m}^{3}$, with a minimum value of $R \$ 9.06 / \mathrm{m}^{3}$ for the species in category C4 (softwood) and a maximum of $R \$ 55.63 / \mathrm{m}^{3}$ for the species of category C1 (special wood). Thus, considering an extraction flow of 30 years and assuming the extraction of $25 \mathrm{~m}^{3} / \mathrm{ha}$ in management designs of forest areas from concession contracts in the state of Pará, it is generate an average economic value of $R \$ 587.00 /$ ha or $R \$ 19.56 /$ ha/year, which is relatively higher than the profit generated by the activities of extensive livestock (around $R \$ 180.00$ per hectare or $R \$ 6.00 /$ ha/year) and grain crops (approximately $R \$ 420.00$ per hectare or $R \$ 14.00 /$ ha/year), which are the main responsibles for deforestation in the Amazon. It also presents a higher profitability than the reforesting with Paricá, whose income is $R \$ 192.26 /$ ha or $R \$ 7.12 /$ ha/year. The marketing margin showed that society tends to appropriate of $14.30 \%$ of the economic value generated in the wood chain from the transition contracts.
\end{abstract}

Keywords:Price of roundwood, Forest concession and Value chain.

\footnotetext{
${ }^{1}$ Recebido em 09.12.2011 e aceito para publicação em 19.04.2012.

2 Universidade Federal Rural da Amazônia, UFRA, Brasil. E-mail<antonio.santana@ufra.edu.br>e < jyared@amazon.com.br>.

${ }^{3}$ Universidade Federal Rural da Amazônia, UFRA. E-mail: <marcos.santos@ ufra.edu.br>.

${ }^{4}$ Universidade Federal do Pará, UFPA, Brasil. E-mail: <alwkynew@ gmail.com>.
} 


\section{INTRODUÇÃO}

O setor florestal é um dos mais importantes da economia paraense pelos empregos, renda e divisas que gera. Em 2008, foi responsável por um valor adicionado de US $\$ 4,46$ bilhões e gerou 30.481 empregos, participando, respectivamente, com $9,6 \%$ e $3,6 \%$ do Produto Interno Bruto (PIB) e do emprego total do Estado do Pará. Nesse mesmo ano, o comércio nacional e internacional apresentou superávit de US\$1,08 bilhão (SANTANA, 2009).

Não obstante esse destaque, a efetividade do marco regulatório da exploração florestal na Amazônia, que a partir de 2004 coibiu intensamente o desmatamento e a extração ilegal de madeira em tora, juntamente com os efeitos da crise econômica internacional a partir de 2007 e o mercado paraense de produtos madeireiros, diminuiu 64,6\% entre 2007 e 2009 , causando forte impacto na indústria madeireira e comprometendo o abastecimento do mercado.

Para atenuar esse problema de abastecimento e contribuir para a recuperação do setor, o Instituto de Desenvolvimento Florestal do Estado do Pará (IDEFLOR) implementou a política de gestão de florestas públicas, por meio de contratos de concessão florestal, com o objetivo de viabilizar a extração dos produtos florestais madeireiros pela iniciativa privada (IDEFLOR, 2010). A região do Baixo Amazonas, além de ser importante polo madeireiro, conforme Santana et al. (2009) e Santos e Santana (2009), abriga grande área de floresta pública destinada às concessões florestais do Estado do Pará.

Para operacionalizar tais contratos, estimou-se o preço da madeira em pé para determinar o valor a ser pago pelas empresas, de acordo com o volume máximo de madeira a ser extraída, estabelecido por meio dos planos de manejo sustentável dessas áreas.

Então, o desafio inicial foi estimar o preço da madeira em pé, a partir do preço de mercado da madeira em tora, dos custos de produção e da margem de lucro. De acordo com Santana et al. (2009), o mercado de madeira em tora do Baixo Amazonas opera em concorrência perfeita. Portanto, o valor econômico da atividade madeireira, determinado a partir do preço de equilíbrio desse mercado, reflete o custo de oportunidade dos contratos de concessão florestal.
O dimensionamento do valor econômico da floresta manejada e sua comparação com as principais alternativas de uso da terra na Amazônia (pecuária extensiva e agricultura de grãos) revelam resultados que confirmam a hipótese de que a exploração sustentável da floresta é mais rentável do que as atividades agropecuárias que, para serem implantadas, exigem a retirada da floresta.

Com isso, a viabilidade econômica da concessão florestal pode contribuir efetivamente para combinar os objetivos de maximização do lucro das empresas com o objetivo da sociedade de minimizar o impacto ambiental das alternativas econômicas de uso do solo no Pará, especificamente na região do Baixo Amazonas, onde estão em implantação os primeiros contratos de concessão gerenciados pelo IDEFLOR.

O objetivo deste trabalho foi estimar o valor econômico da extração manejada de madeira em tora dos contratos de concessão do Baixo Amazonas e sua margem de comercialização até a produção de madeira serrada. Foram utilizados os dados obtidos no projeto de pesquisa "Preço da madeira em pé, valor econômico e mercado de madeira nos contratos de transição do Estado do Pará" desenvolvido por Santana et al. (2010).

\section{MATERIAL E MÉTODOS}

\subsection{Fundamentos teóricos}

O setor florestal mundial passa por um processo de reestruturação produtiva com dinâmicas diferenciadas entre os países produtores e consumidores de madeira tropical, em especial na Amazônia, para onde convergem os esforços visando combater a destruição da floresta. Nesse aspecto, as dimensões econômica e ambiental da sustentabilidade estão mais concretamente incluídas nos contratos de concessão, em razão da maior visibilidade do mercado e das ações dos grupos de interesse. Entretanto, os ganhos sociais da participação coletiva e inclusão das populações tradicionais ainda estão em fase bem inicial, uma vez que o inventário florestal não identifica o potencial dos produtos não madeireiros, bem como não obriga aos proprietários dos contratos de concessão a explorar os resíduos de madeira e viabilizar a inclusão das populações tradicionais locais do entorno dessas áreas de florestas públicas.

As dimensões econômica, ambiental e social da sustentabilidade estão postas nos documentos oficiais do Instituto Brasileiro do Meio Ambiente e dos Recursos 
Naturais Renováveis (IBAMA), Serviço Florestal Brasileiro (SFB) e IDEFLOR, porém a execução deixa em segundo plano ou não contempla parte do capital florestal e as comunidades locais.

Neste trabalho, combinou-se o conceito de valor econômico com a abordagem da cadeia de valor da madeira, adaptado de Porter (1999), envolvendo o conjunto das atividades competitivas implementadas pelas empresas madeireiras, que operam nos elos de produção (manejo e extração) florestal e do desdobramento da madeira em tora (SANTANA, 2002; SANTANA; SANTOS, 2002; SANTANA et al., 2010). Esse ponto é de fundamental importância para criar vantagem competitiva por parte da indústria madeireira paraense, pois iniciativa do tipo vem sendo adotada pelos demais países produtores de madeira tropical (ITTO, 2010; FAO, 2010). Portanto, como estratégia de sobrevivência em longo prazo, a política de concessão florestal deve criar mecanismos para alavancar essa trajetória de desenvolvimento da Amazônia.

As empresas que sobreviveram à crise econômica internacional estão incorporando inovações tecnológicas no processo de produção de madeira em tora (manejo florestal sustentável e reflorestamento), no desdobramento e beneficiamento da madeira (serrada, laminada, compensada) e na indústria de móveis e artefatos, mediante a incorporação de designs, aproveitamento de resíduos (briquetes, pellets, pedaços de madeira) e diferenciação dos produtos finais. Essas ações produziram amplo processo de reestruturação produtiva na indústria madeireira brasileira e, sobretudo, do Estado do Pará, que é o maior produtor e exportador de madeira tropical da Amazônia e do Brasil.

O valor econômico estimado no âmbito da cadeia de valor de Porter (1999) contempla o resultado das diversas atividades que se diferenciam do ponto de vista tecnológico, econômico, ambiental e social, que são desenvolvidas ao longo dos processos produtivos e de gestão das empresas. O valor agregado pela empresa, em cada etapa do processo de produção e comercialização, é mensurado por meio do preço que os clientes estão dispostos a pagar pelo produto. A atividade é economicamente viável quando o valor que a empresa cria é superior ao custo do desenvolvimento da respectiva atividade.
A cadeia de valor contempla três componentes: atividades de apoio, atividades primárias e margem ou valor econômico quando considera o resultado do fluxo líquido atualizado. As atividades de apoio incluem a operacionalização e gestão do plano de manejo e os custos de extração e a infraestrutura. As atividades primárias contemplam a logística operacional, marketing e vendas, os serviços de certificação do produto e a orientação dos produtos para os mercados nacional e internacional. Por fim, a componente margem gera a magnitude da diferença entre o custo unitário e o preço do produto pago pelo cliente, que se transforma em valor econômico líquido ao se considerar o fluxo da exploração manejada de madeira.

Até o momento, como não se conhecia o custo de oportunidade da madeira, em razão da extração ilegal, não era possível determinar a competitividade real das empresas. Todas as estimativas realizadas até então, conforme Santana et al. (2010), superestimam os benefícios privados e subestimam os benefícios sociais. Para os contratos de concessão gerenciados pelo IDEFLOR, o preço da madeira em pé foi definido com base do preço de equilíbrio do mercado da madeira em tora local, que funciona em concorrência perfeita (SANTANA et al., 2009). Assim, considerando a extração manejada de madeira, a determinação do valor econômico permite revelar não apenas a viabilidade do negócio, mas também a base para comparação com o valor gerado nas atividades que estão ligadas diretamente ao desmatamento na Amazônia e cuja justificativa é a rentabilidade substancialmente superior ao que a floresta pode proporcionar.

O conceito de valor econômico foi aplicado apenas ao elo da cadeia produtiva de extração manejada de madeira em tora no Baixo Amazonas. A margem de comercialização contempla os elos de extração e processamento industrial da madeira, nível em que se define o preço equivalente da madeira serrada das espécies extraídas pelas empresas com contratos de concessão florestal.

Como os preços da madeira em pé refletem o custo de oportunidade da atividade florestal manejada, as empresas detentoras dos contratos de concessão podem criar vantagem competitiva em relação às que estão fora do processo e às demais concorrentes no mercado internacional de madeira tropical. Essa perspectiva contribui para que as empresas ampliem o leque de

Revista Árvore, Viçosa-MG, v.36, n.3, p.527-536, 2012 
novas espécies florestais a serem introduzidas no mercado de madeira serrada e aumentem a oferta do produto, uma vez que ainda é grande o estoque desse recurso natural nas áreas destinadas às concessões estadual e federal na Amazônia (SANTANA et al., 2010).

\subsection{METODOS DE ANÁLISE}

A pesquisa foi desenvolvida no polo madeireiro do Baixo Amazonas, uma das regiões pioneiras na implementação dos contratos de concessão florestal gerenciados pelo IDEFLOR. Foram aplicados questionários em seis empresas distribuídas entre os Municípios de Almeirim, Juruti e Santarém. Os levantamentos foram realizados durante o mês de junho de 2010, por ser o período de preços mais baixos para a madeira em tora e madeira serrada. Foram obtidas informações sobre preço da madeira em tora, custos e gestão dos planos de manejo, custo de extração de madeira, transporte das toras e a margem de lucro dos agentes. Também, foram realizadas entrevistas em profundidade com atores-chave de instituições que atuam nessa cadeia produtiva na região.

Neste trabalho, o valor econômico foi estimado para as espécies florestais presentes em todas as empresas entrevistadas com contratos de concessão. Para isso, foram utilizadas as informações do estudo de Santana et al. (2010), trabalho pioneiro que estimou o preço da madeira em pé nos polos madeireiros do Marajó e do Baixo Amazonas. Além da estimação do preço, a determinação do valor econômico da floresta nos contratos de concessão é compartilhada com os grupos de interesse que participam da gestão de florestas públicas do Estado do Pará. A fórmula utilizada no cálculo do valor econômico é especificada a seguir (UNITED NATIONS, 2000):

$$
V E_{i}=\sum_{t=1}^{T}\left[\left(\frac{P_{i t}-C u_{i t}}{(1+r)^{t}}\right) \cdot Q_{i t}\right]=\left(P L a_{i t} \cdot Q_{i t}\right)
$$

em que $V E_{i}$ é o valor econômico da espécie florestal i; $P L a$ é o preço líquido atualizado da espécie florestal i, no período t, em $\mathrm{R} \$ / \mathrm{m}^{3}$; $P$ é o preço da espécie florestal enquadrada na categoria i no mercado local, em $\mathrm{R} \$ / \mathrm{m}^{3}$; $C_{u}$ é o custo unitário de produção da espécie florestal i, no mercado local, em $\mathrm{R} \$ / \mathrm{m}^{3}$ (inclui as atividades de manejo, extração e transporte da madeira em tora); $Q$ é o volume médio de madeira extraída pelas empresas entrevistadas, segundo a categoria, estimado em $25 \mathrm{~m}^{3} / \mathrm{ha}$; $r$ é a taxa de desconto que representa o custo de oportunidade do manejo florestal no mercado local (estimada em $8,5 \%$ ); e $t$ é o horizonte de tempo $(\mathrm{T}=30$ anos $)$ considerado no ciclo de exploração madeireira nas concessões florestais.

Um valor positivo para $V E$ atesta que a atividade é viável economicamente; um valor zero indica neutralidade do resultado e um valor negativo, inviabilidade.

Para determinar a margem de comercialização da madeira na cadeia produtiva, foi necessário calcular o preço equivalente da madeira em tora, multiplicandose o coeficiente de desdobramento pelo preço da madeira serrada, como a seguir (SANTANA, 2002; 2005):

$$
P E M_{i}=K_{d} P M S_{i}
$$

em que:

$P E M_{i}=$ o preço equivalente da madeira da espécie i; $K d=$ o coeficiente de desdobramento da madeira $\left(\mathrm{m}^{3}\right.$ de madeira em tora: $\mathrm{m}^{3}$ de madeira serrada); e

$P M S_{i}=$ o preço da madeira serrada da espécie i.

A partir desse preço foi possível determinar a margem de comercialização da madeira em tora, que representa quanto do valor pago pela madeira serrada é apropriado pelos agentes da comercialização e quanto se destina à sociedade, no caso representado pelo governo. A margem de comercialização total (MCT), conforme Santana (2005), representa a remuneração das operações de comercialização realizadas ao longo do canal de distribuição do produto (custos e margens de lucro). A fórmula é a seguinte:

$$
M C T_{i}=\left(\frac{P E M_{i}-P M P_{i}}{P E M_{i}}\right) \times 100
$$

em que:

$M C T_{i}=$ margem de comercialização total da espécie de madeira i;

$P E M_{i}=$ preço equivalente da madeira da espécie i; e $P M P_{i}=$ preço da madeira em pé

Essa margem de comercialização pode ser desmembrada nas margens do intermediário e das empresas. A margem de comercialização do intermediário é dada por: 


$$
M C I_{i}=\left(\frac{P M T_{i}-P M P_{i}}{P E M_{i}}\right) \times 100
$$

Em que PMT é o preço da madeira em tora da espécie i. A margem de comercialização da empresa é dada por:

$$
M C E_{i}=\left(\frac{P E M_{i}-P M T_{i}}{P E M_{i}}\right) \times 100
$$

A margem social (MS) de comercialização ou a parcela do preço pago pela madeira serrada que fica com a sociedade é obtida, por diferença:

$$
M S_{i}=100-M C_{i}
$$

\section{RESULTADOS}

\subsection{Valor econômico da cadeia}

Na Tabela 1 constam os resultados das estimativas das quantidades e dos valores econômicos médios das categorias de espécies florestais $\mathrm{C} 1$ (quatro espécies), C2 (9 espécies), C3 (9 espécies) e C4 (9 espécies), contemplando as atividades de apoio, atividades primárias e margem da extração de madeira em tora em áreas manejadas. $\mathrm{O}$ valor econômico (VE) foi medido por hectare e por $\mathrm{m}^{3}$. Os resultados discriminados por espécie florestal constam na Tabela 1A (Apêndice) e indicam a viabilidade econômica da extração manejada da madeira em tora.

A média geral dos resultados mostra que foi extraído $0,81 \mathrm{~m}^{3} /$ ha de madeira em tora por espécie florestal, gerando um VE médio para todas as espécies de R \$ 18,94/ha ou $\mathrm{R} \$ 23,48 / \mathrm{m}^{3}$. Considerando todas as espécies e a extração de $25 \mathrm{~m}^{3} / \mathrm{ha}$, em fluxo econômico de 30 anos, nas áreas manejadas dos contratos de concessão, gera-se um valor econômico de R \$ 587,00/ha ou R \$ 19,56/ha/ano.
$\mathrm{Na}$ categoria $\mathrm{C} 1$, que contempla as madeiras especiais de cedro e ipê, tem-se o maior VE médio da produção por $\mathrm{m}^{3}(\mathrm{R} \$ 55,63)$, em função da grande demanda que lhe assegura elevada cotação no mercado de madeira tropical. Entretanto, gera um VE por ha (R \$34,07/ha), o segundo maior entre as categorias, dada à escassez dessas espécies florestais nas áreas de manejo (produção média de $0,25 \mathrm{~m}^{3} / \mathrm{ha}$ ), por causa do longo período de extração ilegal.

As categorias $\mathrm{C} 2$ e $\mathrm{C} 3$ abrigam as madeiras nobres e vermelhas, demandadas pela construção civil rural e urbana, indústria de móveis e artefatos, cercas rurais etc., tanto no mercado nacional quanto internacional. As espécies da categoria $\mathrm{C} 2$ apresentam a maior produção média $\left(1,40 \mathrm{~m}^{3} / \mathrm{ha}\right)$ e VE médio (R\$ $39,98 /$ ha). A categoria C4 (madeira branca), por sua vez, engloba as espécies de menor valor comercial, porém têm ampla utilização na produção de laminados, compensados e artefatos de madeira. Atualmente, em razão da crise financeira e econômica global, a indústria de laminados e compensados de madeira tropical foi fortemente abalada, o que propiciou que a indústria de madeira serrada se inserisse no mercado algumas dessas espécies, inclusive substituindo madeiras enquadradas nas categorias anteriores, tanto na cobertura de residências quanto na indústria de móveis e artefatos. Como resultado, essa categoria de madeira já representa a segunda maior quantidade média produzida nas áreas manejadas $\left(0,72 \mathrm{~m}^{3} / \mathrm{ha}\right)$, gerando um VE médio por espécie de $\mathrm{R} \$ 6,54 /$ ha. O VE médio de $\mathrm{R} \$ 9,06 / \mathrm{m}^{3}$ é ligeiramente inferior ao preço de $\mathrm{R} \$ 10,00 / \mathrm{m}^{3}$ que se paga por $\mathrm{m}^{3}$ de madeira especial ou nobre extraída ilegalmente das áreas não manejadas.

Tabela 1 - Quantidade extraída de madeira e valor econômico em tora dos contratos de concessão do Baixo Amazonas, Estado do Pará.

Table 1 - Amount of wood extracted and the economic value of roundwood of the concession contracts of the Lower Amazon, State of Pará.

\begin{tabular}{lcccc}
\hline Valor médio & Número de espécies & Quantidade Q $\left(\mathrm{m}^{3} / \mathrm{ha}\right)$ & Valor econômico VEa $(\mathrm{R} \$ /$ ha $)$ & Valor econômico VEb $\left(\mathrm{R} \$ / \mathrm{m}^{3}\right)$ \\
\hline Média C1 & 4 & 0,61 & 34,07 & 55,63 \\
Média C2 & 9 & 1,40 & 39,98 & 28,56 \\
Média C3 & 9 & 0,38 & 7,11 & 18,56 \\
Média C4 & 9 & 0,72 & 6,54 & 9,06 \\
\hline Média geral & $\mathbf{3 1}$ & $\mathbf{0 , 8 1}$ & $\mathbf{1 8 , 9 4}$ & $\mathbf{2 3 , 4 8}$ \\
\hline
\end{tabular}

Fonte: Pesquisa de campo.

$\mathrm{VEa}=$ resultado por hectare; $\mathrm{VEb}=$ resultado por $\mathrm{m}^{3} ; \mathrm{e}$ PLa $=$ preço líquido atualizado. 
Tabela 2 - Coeficiente de desdobramento e margens de comercialização da madeira em tora do Baixo Amazonas, Estado do Pará, 2010.

Table 2 - Coefficient of unfolding and trade margins of roundwood at Lower Amazon, State of Pará, 2010.

\begin{tabular}{|c|c|c|c|c|c|}
\hline Valor médio & $\mathrm{Kd}$ & MCT & MCI & MCE & MS \\
\hline Média da categoria C1 & $36,6 \%$ & $74,3 \%$ & $48,8 \%$ & $25,5 \%$ & $25,7 \%$ \\
\hline Média da categoria C2 & $36,8 \%$ & $80,7 \%$ & $45,3 \%$ & $35,4 \%$ & $19,3 \%$ \\
\hline Média da categoria C3 & $37,1 \%$ & $88,5 \%$ & $47,2 \%$ & $41,3 \%$ & $11,5 \%$ \\
\hline Média da categoria C4 & $38,4 \%$ & $92,8 \%$ & $42,3 \%$ & $50,5 \%$ & $7,2 \%$ \\
\hline Média geral & $37,3 \%$ & $85,7 \%$ & $45,4 \%$ & $40,2 \%$ & $14,3 \%$ \\
\hline
\end{tabular}

Fonte: Elaborado a partir da pesquisa de campo.

Notas: Kd é o coeficiente de desdobramento da madeira em tora, MCT é a margem de comercialização total, MCI é a margem de comercialização do intermediário, MCE é a margem de comercialização do empresário e MS é a margem social.

\subsection{Margem de comercialização da madeira em tora}

A Tabela 2 resume os resultados das margens de comercialização e o coeficiente de desdobramento da madeira, utilizado para estimar o preço equivalente da madeira serrada. Esse coeficiente é indicador do nível tecnológico das empresas entrevistadas. Quanto maior o $K_{d}$, maior o aproveitamento da madeira em tora e, consequentemente, menor o volume de resíduo produzido. Os resultados por espécie florestal constam na Tabela $1 \mathrm{~A}$.

Observa-se que a MCT apresentou comportamento inverso ao do VE das madeiras, em que o maior valor foi atribuído às espécies de menor valor econômico da $\mathrm{C} 4$ e o menor das espécies da C1. Isso ocorre em função dos custos de processamento e dos riscos para a inserção do produto no mercado, dada a sua limitada utilização no mercado.

A margem social (MS) ou margem apropriada pelo produtor rural ou caboclo da Amazônia caminha no sentido inverso da MCT, tendo maior participação no negócio das madeiras situadas nas categorias mais nobres.

A média geral de $K_{d}=37,3 \%$ indicou que são necessários $2,8 \mathrm{~m}^{3}$ de madeira em tora para produzir $1,0 \mathrm{~m}^{3}$ de madeira serrada. Esse resultado se deveu ao baixo padrão tecnológico das empresas e aos problemas de rachadura, ocos e nós das toras.

A MCT de $85,7 \%$ indica que para cada $\mathrm{R} \$ 1.000,00$ que os clientes gastam na aquisição de madeira serrada, $\mathrm{R} \$ 857,00$ são apropriados pelos agentes da comercialização, distribuídos entre os intermediários ( $\mathrm{R} \$ 454,00)$ e os empresários ( $\mathrm{R} \$ 402,00)$ e $\mathrm{R} \$ 143,00$ ficam com os produtores. Ou seja, a sociedade se apropria de $14,3 \%$ do valor total do negócio da madeira produzida nos contratos de concessão do Baixo Amazonas.

\section{DISCUSSÃO}

\subsection{Valor econômico da cadeia}

O valor econômico estimado neste trabalho não levou em conta o valor dos resíduos da extração madeireira, que pode ser utilizado na produção de lenha e carvão, e dos produtos não madeireiros, canal importante para alavancar, com a inserção das populações tradicionais, o desenvolvimento local. A razão é que a exploração florestal de tais resíduos e produtos não foi contemplada nos contratos de transição, portanto apresentam custo de oportunidade igual a zero. A cadeia de valor também não foi analisada do ponto de vista da identificação da estrutura de poder dos agentes e da governança, conforme GTZ (2007), tendo em vista captar o grau de influência da cadeia no empoderamento das populações locais e da capacidade de contribuir para um desenvolvimento com a inclusão das populações mais pobres. A razão é que a cadeia de valor da madeira não está estruturada, uma vez que a população local não exerce papel definido como agente de decisão na área do estudo.

O valor econômico estimado foi superior ao gerado pelas atividades que concorrem para a retirada da floresta, como o sistema de produção de soja ( $\mathrm{R} \$ 420,00 /$ ha ou R $\$ 14,00 /$ ha/ano) e o sistema de pecuária extensiva (R\$ 180,00/ha ou R \$ 6,00/ha/ano) (SANTANA; AMIN, 2002; SANTANA et al., 2006). Este resultado é diferente dos relacionados na literatura, conforme Karsenty et 
Tabela 1A - Preço Líquido atualizado (PLa), Quantidade (Q), Valor Econômico (VE), Preços da Madeira em Pé (PMP), Preço da Madeira em Tora (PMT), Preço da Madeira Serrada (PMS) e margens de comercialização, polo Baixo Amazonas, Estado do Pará, 2010.

Table 1A - Updated net prices (PLa), Quantity (Q), Economic Value (VE), Prices of Standing Timber (PMP), Prices of Roundwood (PMT), Prices of Lumber (PMS) and trade margins, in Lower Amazon, State of Pará, 2010.

\begin{tabular}{|c|c|c|c|c|c|c|c|c|c|c|c|}
\hline Nom & Tome & PLa & QP & VE & PMP & PMT & PMS & Kd & MTC & MCI & MCE \\
\hline Ipê & $\begin{array}{l}\text { Tabebuia serratifolia (Vahl) } \\
\text { Nichols. }\end{array}$ & 65,00 & 1,40 & 91,00 & 95,00 & 285,00 & 970,00 & $38,2 \%$ & $74,4 \%$ & $51,3 \%$ & $23,1 \%$ \\
\hline Cedro & Cedrela odorata $\mathrm{L}$. & 61,50 & 0,15 & 9,23 & 91,00 & 275,00 & 950,33 & $40,7 \%$ & $76,5 \%$ & $47,6 \%$ & $28,8 \%$ \\
\hline Cumaru & Dipteryx odorata (Aubl.) Willd. & 47,00 & 0,65 & 30,55 & 83,00 & 230,00 & 900,00 & $33,3 \%$ & $72,3 \%$ & $49,0 \%$ & $23,3 \%$ \\
\hline Freijó & Cordia goeldiana Huber & 49,00 & 0,25 & 12,25 & 81,00 & 230,00 & 925,00 & $34,0 \%$ & $74,2 \%$ & $47,4 \%$ & $26,9 \%$ \\
\hline \multicolumn{2}{|c|}{ Média da categoria $\mathrm{C} 1$} & 55,63 & 0,61 & $\mathbf{3 4 , 0 7}$ & 87,50 & 255,00 & 936,33 & $36,6 \%$ & $74,3 \%$ & $48,8 \%$ & $25,5 \%$ \\
\hline Jatobá & Hymenaea courbaril & 61,50 & 2,15 & 132,23 & 63,50 & 230,00 & 870,00 & $32,8 \%$ & $77,7 \%$ & $58,3 \%$ & $19,4 \%$ \\
\hline Maçara & $\begin{array}{l}\text { Manilkara huberi (Ducke) } \\
\text { Chevalier }\end{array}$ & 26,00 & 4,75 & 123,50 & 62,00 & 190,00 & 870,00 & $33,6 \%$ & $78,8 \%$ & $43,8 \%$ & $35,0 \%$ \\
\hline Angelim & Dinizia excelsa Ducke & 20,00 & 1,95 & 39,00 & 61,00 & 186,00 & 808,33 & $44,5 \%$ & $83,0 \%$ & $34,8 \%$ & $48,3 \%$ \\
\hline Muiracatiara & Astronium ulei Mattick & 25,00 & 0,60 & 15,00 & 57,00 & 187,00 & 816,67 & $38,3 \%$ & $81,8 \%$ & $41,5 \%$ & $40,3 \%$ \\
\hline Sucupira & Bowdichia nitida Spruce & 25,50 & 0,15 & 3,83 & 56,50 & 186,00 & 900,00 & $35,2 \%$ & $82,2 \%$ & $40,9 \%$ & $41,3 \%$ \\
\hline Goiabão & Pouteria pachycarpa Pires & 25,50 & 0,10 & 2,55 & 56,50 & 186,00 & 770,00 & $37,0 \%$ & $80,2 \%$ & $45,5 \%$ & $34,7 \%$ \\
\hline Itaúba & $\begin{array}{l}\text { us itauba (Meisn.) } \\
\text { Mez }\end{array}$ & 28,50 & 1,65 & 47,03 & 55,50 & 186,00 & 800,00 & $39,2 \%$ & $82,3 \%$ & $41,6 \%$ & $407 \%$ \\
\hline Louro & spixiana (Nees) Mez. & 13,00 & 0,75 & 9,75 & 52,00 & 168,00 & 687,50 & $37,8 \%$ & $80,0 \%$ & $44,7 \%$ & $35,3 \%$ \\
\hline Amarelão & iocarpa (Vogel) J.F. & 2,00 & 50 & 160 & 47,00 & 184 & 33 & $33,0 \%$ & $\%$ & $56,6 \%$ & $4,0 \%$ \\
\hline \multicolumn{2}{|c|}{ Média da categoria C2 } & 28,56 & 1,40 & 39,98 & 56,78 & 189,22 & 806,20 & $36,8 \%$ & $80,7 \%$ & $45,3 \%$ & $35,4 \%$ \\
\hline Tatajuba & Bagas & 35,00 & 0,60 & 21,00 & 38,00 & 180,00 & 763,33 & $33,5 \%$ & $85,1 \%$ & $55,5 \%$ & $29,6 \%$ \\
\hline Quaruba & Vochysia paraensis Ducke & 24,50 & 0,75 & 18,38 & 35,50 & 170,00 & 686,67 & $48,3 \%$ & $89,3 \%$ & $40,5 \%$ & $48,8 \%$ \\
\hline Maparajuba & (2) & 13,00 & 0,10 & 1,30 & 32,00 & 150,00 & 883,33 & $34,7 \%$ & $89,6 \%$ & $38,5 \%$ & $51,0 \%$ \\
\hline Garapeira & ocarpa (Vogel) & 28,00 & 0,50 & 14,00 & 31,00 & 165,00 & 680,00 & $33,6 \%$ & $86,4 \%$ & $58,6 \%$ & $27,8 \%$ \\
\hline Pau-amarelo & Euxylophora paraensis & 6,50 & 0,05 & 0,33 & 27,50 & 130 & 0 & $33,2 \%$ & $89,2 \%$ & $40,3 \%$ & $48,9 \%$ \\
\hline Pau-roxo & Peltogyne paradoxa Ducke & 4,50 & & & & & 746,00 & $33,2 \%$ & $88,1 \%$ & $40,6 \%$ & $47,5 \%$ \\
\hline Cedrorana & Vochysia maxima Ducke & 23,00 & 0,20 & 4,60 & 27,00 & 154,00 & 670,00 & $44,0 \%$ & $90,8 \%$ & $43,1 \%$ & $47,8 \%$ \\
\hline Andiroba & Carapa guianensis Aubl. & 20,00 & 0,75 & 15,00 & 25,00 & 150,00 & 712,00 & $36,8 \%$ & $90,5 \%$ & $47,7 \%$ & $42,8 \%$ \\
\hline Faveira & suaveolens Miq. & 12,50 & 0,45 & 5,63 & 24,50 & 141,00 & 533,33 & $36,3 \%$ & $87,4 \%$ & $60,1 \%$ & $27,2 \%$ \\
\hline \multicolumn{2}{|c|}{ Média da categoria C3 } & 18,56 & 0,38 & 7,11 & 30,00 & 152,22 & 715,63 & $37,1 \%$ & $88,5 \%$ & $47,2 \%$ & $41,3 \%$ \\
\hline Piquiá & Caryocar microcarpum Ducke & 12,50 & 1,65 & 20,63 & 18,50 & 123,00 & 630,00 & $39,8 \%$ & $92,6 \%$ & $41,7 \%$ & $50,9 \%$ \\
\hline Cupiúba & Goupia glabra Aubl. & 10,00 & 1,80 & 18,00 & 18,00 & 120,00 & 672,00 & $36,8 \%$ & $92,7 \%$ & $41,2 \%$ & $51,5 \%$ \\
\hline Melancieira & Alexa grandiflora Ducke & 12,00 & 0,25 & 3,00 & 18,00 & 120,00 & 600,00 & $34,8 \%$ & $91,4 \%$ & $48,9 \%$ & $42,4 \%$ \\
\hline Mandioqueira & Qualea lancifolia Ducke & 12,00 & 0,25 & 3,00 & 18,00 & 120,00 & 616,00 & $41,8 \%$ & $93,0 \%$ & $39,6 \%$ & $53,4 \%$ \\
\hline Curupixá & Micropholis nelioniana & 12,50 & 0,75 & 9,38 & 17,50 & 110,00 & 712,50 & $37,3 \%$ & $93,4 \%$ & $34,9 \%$ & $58,6 \%$ \\
\hline Amesclão & Trattinnickia rhoifolia Willd. & 8,00 & 0,90 & 7,20 & 16,00 & 120,00 & 600,00 & $42,0 \%$ & $93,7 \%$ & $41,3 \%$ & $52,4 \%$ \\
\hline Copaíba & Copaifera guianensis Desf. & 6,50 & 0,75 & 4,88 & 16,50 & 118,00 & 600,00 & $34,5 \%$ & $92,0 \%$ & $49,0 \%$ & $43,0 \%$ \\
\hline Angico & Pseudopiptadenia suaveolens & 4,00 & 0,10 & 0,40 & 16,00 & 115,00 & 550,00 & $40,0 \%$ & $92,7 \%$ & $45,0 \%$ & $47,7 \%$ \\
\hline Amapá & Brosimum parinarioides Ducke & 4,00 & 0,05 & 0,20 & 16,00 & 115,00 & 662,50 & $38,5 \%$ & $93,7 \%$ & $38,8 \%$ & $54,9 \%$ \\
\hline \multicolumn{2}{|c|}{ Média da categoria C4 } & 9,06 & 0,72 & 6,54 & 17,17 & 117,89 & 627,00 & $38,4 \%$ & $92,8 \%$ & $42,3 \%$ & $50,5 \%$ \\
\hline \multicolumn{2}{|l|}{ Média geral } & 23,48 & 0,81 & 18,94 & 41,47 & 166,26 & 744,67 & $37,3 \%$ & $85,7 \%$ & $45,4 \%$ & $40,2 \%$ \\
\hline
\end{tabular}

Fonte: Elaborado a partir da pesquisa. 
al. (2010), em que a floresta manejada gera renda inferior às atividades agrícola, pecuária e de reflorestamento. Especialmente na Amazônia, onde ainda não se conhece o valor da atividade florestal madeireira, já que sob o sistema tradicional de uso do solo o preço das árvores é próximo de zero.

Nos sistemas atuais de uso do solo na Amazônia, a venda das árvores de maior valor comercial para os madeireiros geralmente se destinava a custear parte do desmatamento e implantação de atividades agrícolas e pastagens para a criação de gado (SANTANA, 2002). Confirmam-se, portanto, os resultados de Santana et al. (1997) e Santana (2008) de que a agricultura tradicional e a pecuária extensiva praticadas na Amazônia se desenvolvem à custa da exploração dos recursos naturais e da mão de obra informal.

A extração florestal madeireira regulada pelos contratos de concessão também pode apresentar maior rentabilidade do que o reflorestamento. Um reflorestamento com paricá implantado na microrregião de Paragominas, com fluxo de 28 anos, produtividade de $200 \mathrm{~m}^{3} /$ ha e preço de $\mathrm{R} \$ 70,00 / \mathrm{m}^{3}$, gera margem de valor econômico de R \$ 192,26/ha, ou R \$ 6,87/ha/ano, de acordo com os coeficientes obtidos em Vale (2010). Outros resultados sobre o retorno econômico dos sistemas agroflorestais comparativamente com sistemas agrícolas tradicionais, considerando o risco, pode ser encontrado em Varela e Santana (2009). Nesse caso, especificamente os SAFs analisados em Tomé-Açu apresentaram rentabilidade superior à exploração manejada de madeira. Portanto, a gestão de florestas públicas por meio dos contratos de concessão é alternativa economicamente viável que deve integrar-se à carteira de negócios formada pelos sistemas produtivos de base agrária do Estado do Pará.

Observa-se pelos resultados da Tabela 1 que, mesmo na situação em que a floresta manejada contemple apenas madeira branca (categoria C4), o valor econômico total estimado seria de $\mathrm{R} \$ 436,50 /$ ha, portanto superior ao gerado nas alternativas de produção agropecuária. A razão para essa maior rentabilidade econômica se deve ao baixo custo de produção, uma vez que a dependência de insumos modernos é insignificante fora do ano em que se realiza a colheita das árvores.

Como em todas as áreas de concessão constam espécies das quatro categorias, a extração manejada de madeireira na Amazônia torna-se economicamente viável, o que deve despertar o interesse dos empresários e dos órgãos de fomento para investir nesse negócio.

\subsection{Margem de comercialização da madeira em tora}

A análise da cadeia de valor, embora considere pioneiramente o preço da madeira em pé, avançou até a fabricação de madeira serrada. Estudos posteriores devem complementar a análise incorporando os elos de produção de móveis e artefatos de madeira, tendo em vista a inserção desses produtos nos mercados local, nacional e internacional.

A margem de comercialização dos intermediários (MCI), ou seja, dos produtores que vendem madeira em tora no mercado local ou dos extratores que adquirem a madeira de comunidades locais e de planos de manejo (conhecidos como "toreiros"), mas não fazem o desdobramento da madeira, têm a maior parcela da margem de comercialização, uma vez que arcam com os custos de extração da madeira e transporte até a beira dos rios ou das estradas vicinais para o embarque do produto. Para esses agentes, as espécies enquadradas nas $\mathrm{C} 2$ e C4 apresentam as menores margens de comercialização e nas categorias C1 e C3 as maiores. As espécies da categoria $\mathrm{C} 1$ possuem maiores custos de extração, transporte e impostos relativamente mais elevados e preço da madeira em tora também relativamente mais alto, enquanto as espécies da categoria C3 têm custos e margens de lucro elevados em função do risco de preço do mercado da madeira em tora, o que torna a margem relativamente maior.

No caso dos empresários que adquirem a madeira em tora, a margem de comercialização (MCE) é menor do que a margem do intermediário, porque adiciona ao preço da madeira em tora apenas os custos de transporte e desdobramento da madeira. A margem cresce no mesmo sentido da MCT, com a menor margem para as madeiras da $\mathrm{C} 1 \mathrm{e}$ a maior para as madeiras da categoria C3. No entanto, as empresas verticalizadas, ou seja, aquelas que realizam todas as etapas da extração ao desdobramento, se apropriam de toda a margem de comercialização. Assim, a madeireira busca equilibrar sua margem de lucro com as madeiras de menor valor comercial, cujos estoques naturais são substancialmente mais abundantes e diversificados. Este resultado, conforme IDEFLOR (2010), explica as razões para a representação dos madeireiros que têm contratos de transição reivindicar redução nos preços das madeiras de menor valor comercial. 
A pesquisa de campo revelou número considerável de espécies florestais que antes eram enquadradas como "madeira branca" e desconhecidas do mercado de madeira serrada pelas indústrias de móveis e artefatos e da construção, mas atualmente estão ganhando parcela do mercado em razão da coloração e da adequabilidade à fabricação de móveis, artefatos e madeira para cobertura de casas, fabricação de portas, janelas etc. Esses resultados estão sendo revelados agora, conforme Santana et al. (2010) e Itto (2010), pois a crise econômica internacional colocou um ponto de inflexão na trajetória da indústria de laminados e compensados à base de madeira tropical, sobretudo da Amazônia. Portanto, algumas empresas estão criando vantagem competitiva, a partir das oportunidades que surgiram com a crise financeira internacional e com a nova dinâmica da política ambiental brasileira.

\section{CONCLUSÕES}

A extração manejada de madeira das áreas de concessão florestal do Estado do Pará é atividade economicamente viável.

O valor econômico médio da extração manejada de madeira em tora no Baixo Amazonas foi de $\mathrm{R} \$ 23,48 / \mathrm{m}^{3}$, assumindo valor mínimo de $\mathrm{R} \$ 9,06 / \mathrm{m}^{3}$ para as espécies da categoria C4 e um máximo de $\mathrm{R} \$ 55,63 / \mathrm{m}^{3}$ para as espécies da categoria $\mathrm{C} 1$. Assim, para uma extração de $25 \mathrm{~m}^{3} /$ ha de madeira nas áreas de florestas manejadas dos contratos de concessão do Estado do Pará, em fluxo econômico de 30 anos, gera-se um valor econômico de R \$ 587,00/ha ou $\mathrm{R} \$ 19,56 / \mathrm{ha} /$ ano. Esse resultado é superior ao gerado pelas atividades de pecuária extensiva (em torno de $\mathrm{R} \$ 180,00 /$ ha ou $\mathrm{R} \$ 6,00 / \mathrm{ha} / \mathrm{ano})$, das lavouras de grãos (em torno dos $\mathrm{R} \$ 420,00 /$ ha ou de $\mathrm{R} \$ 14,00 / \mathrm{ha} / \mathrm{ano}$ ), principais responsáveis pelo desmatamento da Amazônia.

A extração manejada de madeira das áreas de concessão florestal do Estado do Pará, ao contrário do esperado, apresenta valor econômico superior à agricultura tradicional de grãos e à pecuária extensiva, o que sinaliza para a eficiência econômica da gestão de florestas públicas na Amazônia.

Os produtores de madeira em tora, juntamente com a produção comunitária, dominam, em média, 14,30\% do valor econômico do negócio da madeira, e os $85,70 \%$ restantes ficam com as empresas florestais, ou seja, a sociedade se apropria de 14,3\% desse negócio. Assim, a cada $\mathrm{R} \$ 1.000,00$ gastos na aquisição de madeira serrada, $\mathrm{R} \$ 143,00$ ficam com a sociedade (valor arrecadado pelo governo) e $\mathrm{R} \$ 857,00$ ficam com os intermediários e empresários do setor florestal.

A política de concessão florestal subestima o valor socioeconômico e ambiental da floresta, uma vez que apenas a madeira em tora está em pauta, não havendo efetividade no aproveitamento dos resíduos de madeira, e não computa o valor dos produtos não madeireiros e os serviços ambientais da floresta, assim como limita sua eficácia ao dificultar a participação de micro e pequenas empresas locais e das comunidades tradicionais.

\section{AGRADECIMENTOS}

Ao Instituto de Desenvolvimento Florestal do Estado do Pará (IDEFLOR), pelo financiamento do projeto de pesquisa "Preço da madeira em pé, valor econômico e mercado de madeira nos contratos de transição do Estado do Pará"; e à Fundação de Apoio à Pesquisa, Extensão e Ensino em Ciências Agrárias (FUNPEA), pelo gerenciamento dos recursos.

\section{REFERÊNCIAS}

FAO. Food and Agriculture Organization of the United Nations. Evaluación de los recursos forestales mundiales 2010 . Disponível em: <http://www.fao.org/forestry/ fra2020> Acesso em: maio de 2010.

GTZ. Manual valuelinks: metodologia de promoção da cadeia de valor. GTZ, 2007.

IDEFLOR. Instituto de Desenvolvimento Florestal do Estado do Pará. Orientação de pagamento - contratos de transição. Disponível em: <http://www.ideflor.pa.gov.br> Acesso em: 08 de março de 2010.

INTERNATIONAL TROPICAL TIMBER ORGANIZATION - ITTO. Annual review and assessment of the world timber situation, 2008. Disponível em: <http:// www.itto.org.jp/> Acessado em: 05 de jul. de 2010.

KARSENTY,A. et al. Regulating industrial forest concessions in Central Africa and South America. Forest Ecology and Management, v.256, p.1498-1508, 2008. Disponível em: <http://ww.elsevier.com/ locale/foreco>Acesso em: 13 de ago. de 2010.

Revista Árvore, Viçosa-MG, v.36, n.3, p.527-536, 2012 
PORTER, M. E. Vantagem competitiva. Rio de Janeiro: Campus, 1999.

PORTER, M. E.; MILLAR, V. E. Como a informação proporciona vantagem competitiva. In: PORTER, M. E. Competição; on competition: estratégias competitivas essenciais. Rio de Janeiro: Campus, 1999. p.83-106.

SANTANA, A. C. A competitividade sistêmica das empresas de madeira da Região Norte. Belém: FCAP, 2002.

SANTANA, A. C.; AMIN, M. M. Cadeias produtivas e oportunidades de negócio na Amazônia. Belém: UNAMA, 2002.

SANTANA, A. C. Elementos de economia, agronegócio e desenvolvimento local. Belém: GTZ/TUD/UFRA, 2005.

SANTANA, A. C.; FILGUEIRAS, G. C.; ROCHA, C. F. G. Arranjos produtivos locais da BR263: contribuições ao planejamento estratégico territorial. Belém: ADA, 2006.

SANTANA, A. C. Cadeias produtivas setoriais e o curso do desenvolvimento local na Amazônia. In: Agricultura Tropical: quatro décadas de inovações tecnológicas, institucionais e políticas. Brasília: Embrapa, 2008. v.2. p.275-291.

SAntana, A. C. Análise das contas correntes do balanço de pagamentos interestadual do estado do Pará, período 2005 a 2008. Belém: UFRA/UFPA/ BNDES, 2009.

SANTANA, A. C. et al. Reestruturação produtiva e desenvolvimento na Amazônia. Belém: BASA/FCAP, 1997.
SANTANA, A. C.; SANTOS, M. A. S.; OLIVEIRA, C. M. Preço da madeira em pé, cadeia de valor e mercado de madeira nos pólos do Marajó e baixo Amazonas. Belém: IDEFLOR/UFRA, 2010.

SANTANA, A. C. et al. Caracterização do mercado de produtos florestais madeireiros e não-madeireiros da região Mamuru-Arapiuns, 2009. (Relatório de Pesquisa, 1).

SANTANA, A. C.; SANTOS, M. A. S. Estrutura de mercado e competitividade da indústria de madeira e artefatos da Amazônia. Unama: Movendo Idéias, v.7, n.11, p.13-26, 2002.

SANTOS, R. B. N.; SANTANA, A. C.

Comportamento recente do setor florestal madeireiro no estado do Pará, Brasil. Revista Árvore, v.33, n.3, p.533-543, 2009.

UNITED NATIONS. Integrated environmental and economic accounting: an operational manual. New York: 2000. (Series F, 78)

VALE, F. A. F. Sustentabilidade de sistemas de produção florestal no estado do Pará. 2010. Dissertação (Mestrado em Ciências Florestais) Universidade Federal Rural da Amazônia, Belém, 2010.

VARELA, L. B.; SANTANA, A. C. Aspectos econômicos da produção e dos riscos nos sistemas agroflorestais e nos sistemas tradicionais de produção agrícola em ToméAçu, Revista Árvore, v.33, n.1, p.151$160,2009$. 